Research Article

\title{
Clinical and molecular characterization of a Brazilian cohort of campomelic dysplasia patients, and identification of seven new SOX9 mutations
}

\author{
Eduardo P. Mattos ${ }^{1,2}$, Maria Teresa V. Sanseverino ${ }^{1}$, José Antônio A. Magalhães ${ }^{3}$, Júlio César L. Leite ${ }^{1}$, \\ Temis Maria Félix ${ }^{1}$, Luiz Alberto Todeschini ${ }^{3}$, Denise P. Cavalcanti ${ }^{4}$ and Lavinia Schüler-Faccini ${ }^{1,2}$ \\ ${ }^{1}$ Serviço de Genética Médica, Hospital de Clínicas de Porto Alegre, Porto Alegre, RS, Brazil. \\ ${ }^{2}$ Departamento de Genética, Universidade Federal de Rio Grande do Sul, Porto Alegre, RS, Brazil. \\ ${ }^{3}$ Faculdade de Medicina, Universidade Federal de Rio Grande do Sul, Porto Alegre, RS, Brazil. \\ ${ }^{4}$ Grupo de Displasias Esqueléticas, Departamento de Genética Médica, Faculdade de Medicina, \\ Universidade Estadual de Campinas, Campinas, SP, Brazil.
}

\begin{abstract}
Campomelic dysplasia (CD) is an autosomal, dominantly inherited, skeletal abnormality belonging to the subgroup of bent bone dysplasias. In addition to bowed lower limbs, CD typically includes the following: disproportionate short stature, flat face, micrognathia, cleft palate, bell-shaped thorax, and club feet. Up to three quarters of $46, \mathrm{XY}$ individuals may be sex-reversed. Radiological signs include scapular and pubic hypoplasia, narrow iliac wings, spaced ischia, and bowed femora and tibiae. Lethal CD is usually due to heterozygous mutations in SOX9, a major regulator of chondrocytic development. We present a detailed clinical and molecular characterization of nine Brazilian CD patients. Infants were either stillborn $(n=2)$ or died shortly after birth and presented similar phenotypes. Sex-reversal was observed in one of three chromosomally male patients. Sequencing of SOX9 revealed new heterozygous mutations in seven individuals. Six patients had mutations that resulted in premature transcriptional termination, while one infant had a single-nucleotide substitution at the conserved splice-site acceptor of intron 1. No clear genotype-phenotype correlations were observed. This study highlights the diversity of SOX9 mutations leading to lethal $\mathrm{CD}$, and expands the group of known genetic alterations associated with this skeletal dysplasia.
\end{abstract}

Keywords: campomelic dysplasia, skeletal dysplasia, osteochondrodysplasias, SOX9, prenatal diagnosis.

Received: May 8, 2014; Accepted: August 19, 2014.

\section{Introduction}

Campomelic dysplasia $(\mathrm{CD})$ is an autosomal dominant condition classified among the bent bone skeletal dysplasias (Warman et al., 2011). Typical manifestations of $\mathrm{CD}$ include shortening and bowing of the long bones, hypoplasia of the scapula, absence of ossification of the dorsal vertebral pedicles, and an abnormal pelvic bone pattern, with narrow iliac wings, spaced ischia, and hypoplastic/absent pubis bones. These findings warrant the diagnosis of $\mathrm{CD}$ in both prenatal ultrasonographic evaluation and postnatal radiological examination.

Clinically, CD is characterized by disproportionally short stature, short and bowed limbs, pretibial skin dimples, club feet, hip dislocation, thoracic constriction, cleft palate, micro- and/or retrognathia, and midface hypoplasia (Maroteaux et al., 1971; Spranger et al., 2002). Additionally, up to three quarters of karyotypically male

Send correspondence to Maria Teresa Vieira Sanseverino. Serviço de Genética Médica, Hospital de Clínicas de Porto Alegre, Rua Ramiro Barcelos, 2350, 90035-903 Porto Alegre, RS, Brazil. E-mail: msanseverino@ hcpa.ufrgs.br.
$(46, \mathrm{XY})$ patients are sex-reversed, with phenotypically normal external female genitalia (Massardier et al., 2008). Most infants with typical CD die shortly after birth due to pulmonary hypoplasia. However, patients diagnosed with a $\mathrm{CD}$ variant known as acampomelic campomelic dysplasia (ACD) usually survive the neonatal period and may reach adult life without major disabilities, but give birth to affected children (Gordon et al., 2009; Lecointre et al., 2009).

$\mathrm{CD}$ has been the subject of intense investigation for over twenty years, since its original genetic linkage to human chromosome 17 (Tommerup et al., 1993) and the subsequent characterization of SOX9 as the locus involved (Foster et al., 1994; Wagner et al., 1994). The vast majority of CD cases (as well as some ACD cases) are attributed to haploinsufficiency, due to de novo mutations in the coding region of SOX9, a master regulator of chondrogenesis and SRY-mediated testicular development (Foster et al., 1994; Wagner et al., 1994; Gordon et al., 2009). Conversely, a greater proportion of ACD patients is characterized by genomic imbalances in the vicinity of SOX9, a gene desert 
region that encompasses approximately $2 \mathrm{Mb}$ in chromosome 19q24.3-25 (Gordon et al., 2009).

In this paper, we present nine Brazilian CD patients who were diagnosed either prenatally or shortly after birth. Major clinical and radiologic findings are detailed for all cases. Sequencing of SOX9 revealed mutations in seven of them, all of which had not been previously described. This work is a report on one of the largest cohorts of $\mathrm{CD}$ patients, and it highlights the mutational diversity of SOX9 mutations.

\section{Material, Subjects and Methods}

From April 2012 to November 2013, clinical data from patients suspected of having CD were either retrospectively (for patient 1 and patients 3 to 7 ) or prospectively (patients 2, 8, and 9) referred to our Institution from different Brazilian medical genetics services, and here they were evaluated by two clinical geneticists (MTVS or DPC). Photographs, radiographs, and medical records were used to characterize the findings of each patient, both clinically and radiologically. Standard growth curves were utilized to determine percentiles for birth length (BL), birth weight $(\mathrm{BW})$, and occipitofrontal circumference (OFC).

DNA was extracted from peripheral blood and used to amplify all exons and exon-intron boundaries of SOX9 by polymerase chain reaction (PCR), in nine patients. For patient 9 only, DNA from both parents was also obtained. Amplification products were purified by treatment with an exonuclease I / shrimp alkaline phosphatase protocol and subjected to conventional Sanger sequencing using an ABI 3130xl Genetic Analyzer (Applied Biosystems). CodonCode Aligner software, version 4.2.1 demo (CodonCode Corporation), was used to align sequences and analyze electropherograms. SOX9 reference sequences ENSG00000125398.5 (genomic) and ENSP00000245479.2 (protein) from ENSEMBL were used as wild type references. Nucleotide numbering of mutations followed the base positions of SOX9 cDNA reference sequence CCDS_11689.1 from NCBI.

When the karyotype was not available, the genotypic sex of patients was inferred from the amplification of $X$ and $\mathrm{Y}$ chromosome-specific sequences in zinc finger protein, $X$-linked $(Z F X)$, and sex determining region $Y(S R Y)$ genes, respectively. Primer sequences and PCR conditions are available upon request. The Spliceman web server (Lim and Fairbrother, 2012) was used to estimate the pathogenicity of the splice-site mutation identified in patient 3 .

Ethical approval for this study was obtained from both the Institutional Review Board of the Hospital de Clínicas de Porto Alegre, and the Brazilian National Committee for Ethics in Research (project number 07044212.3.0000.5327).

\section{Results}

The main clinical data from the nine CD patients are summarized in Table 1. Examples of typical clinical and radiological findings are also illustrated in Figure 1. All infants displayed the typical CD phenotype, and they were either stillborn or died shortly after birth. Sex reversal was found in one of the 46,XY patients (patient 7). The mean gestational age (GA) at birth, considering live births only, was $36.4 \pm 2.5$ weeks. BW was within the normal range in the majority of patients (mean $=2,672.8 \pm 699.0 \mathrm{~g}$ ), while BL was below the $10^{\text {th }}$ percentile in all patients whose measurement data were available $($ mean $=40.7 \pm 3.1 \mathrm{~cm})$. Most infants had macrocephaly, with OFCs above the $90^{\text {th }}$ percentile for the GA (mean $=36.1 \pm 1.8 \mathrm{~cm})$. No live born infants survived the neonatal period. Shortened and bowed limbs were found in all patients - additional dysmorphic features are detailed in Table S1. Of note, craniofacial anomalies (micro/retrognathia, flat face, flat nasal bridge) were highly prevalent in this cohort. Post-natal radiographies were obtained for all patients - a detailed assessment of skeletal abnormalities is presented in Table S2. Bowing of the femora and tibia and malformation of the pelvic bones were consistently found.

DNA was available for molecular analysis for all patients, and putative pathogenic heterozygous SOX9 mutations were found in seven individuals, which equates to a mutational detection rate of $78 \%$ (see Table 1). Mutations shown in Figure 2 for patients 1, 2, 5, 6, 8, and 9 predicted the insertion of a premature termination codon, either due to a stop codon mutation (patients 2, 5, and 6), or a frame shift mutation (patients 1, 8, and 9).

An A-to-G substitution was identified in the conserved 3' splice-site of intron 1 of patient 3. In silico analysis using the Spliceman web server, which ranks putative donor and acceptor splice-site mutations based on exon/intron sequence conservation among different species, predicted a pathogenic consequence for this mutation, with a probability of $67 \%$. Representative sequencing results are shown in \pm for each patient with an identified mutation. Because of the absence of DNA from parents in most cases, molecular confirmation of a de novo mutation was only possible for patient 9 , although parents of all patients were phenotypically normal.

\section{Discussion}

In this study, we sought to characterize a large cohort of CD patients in Brazil at the clinical, radiological and molecular levels. Our study recapitulated several observations previously reported, and this illustrated a striking degree of homogeneity among CD patients, considering clinical and radiological findings. We were able to identify different heterozygous mutations in the coding region of $\mathrm{SOX} 9$, in seven of the nine patients. However, not unlike others (Wagner et al., 1994; Kwok et al., 1995; Meyer et al., 


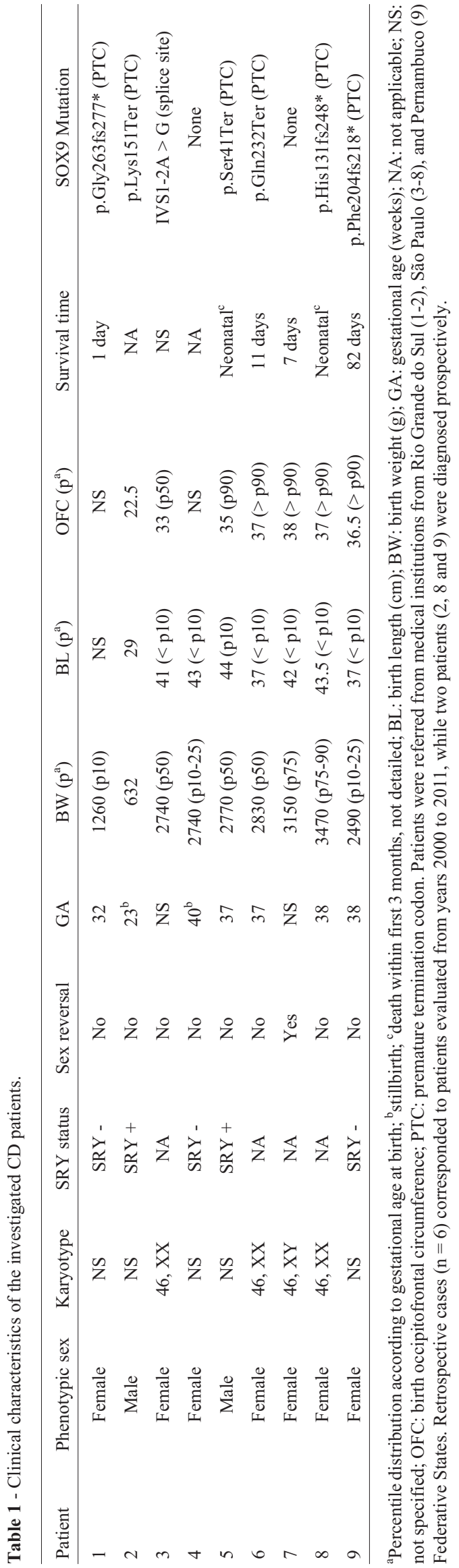

1997), a subset of the screened patients (2 out of 9) did not have any nucleotide variation in the coding region of SOX9. Of course, a heterozygous deletion within SOX9 or imbalances of regulatory elements in its genomic vicinity cannot be ruled out. These hypotheses shall be further investigated for patients 4 and 7 .

Although SOX9 is a small gene, spanning little more than $5 \mathrm{~kb}$ and three exons, a plethora of studies have characterized regulatory DNA elements located both upstream and downstream from the gene that regulates SOX9 expression, both temporally and tissue-specifically (Bagheri-Fam et al., 2006). For instance, cumulative evidence has suggested that a $78 \mathrm{~kb}$ genomic region upstream from SOX9 plays a role in testicular expression, given that deletion of this putative regulatory element has been observed in some 46,XY sex-reversed individuals (Pop et al., 2004). Likewise, isolated Pierre-Robin (Fukami et al., 2012), brachydactyly-anonychia (Kurth et al., 2009), and congenital heart defects (Sanchez-Castro et al., 2013) have already been linked to pathological copy number variations of putative regulators of SOX9 expression in this chromosomal region.

Different studies have tried to establish genotypephenotype correlations in $\mathrm{CD} / \mathrm{ACD}$, but these have mostly remained elusive (Wagner et al., 1994; Meyer et al., 1997; Ninomiya et al., 2000; Pop et al., 2005). Mutations in SOX9 also display a great degree of variable expressivity (Cameron et al., 1996). Moreover, it has been demonstrated that patients with the same SOX9 mutation may develop $\mathrm{CD}$ or $\mathrm{ACD}$, have different degrees of sexual development disorders, and even stark differences in survival (Wagner et al., 1994; Meyer et al., 1997; McDowall et al., 1999; Friedrich et al., 2000; Moog et al., 2001; Wada et al., 2009).

Since changes in SOX9 associated with CD are mainly private mutations, the alterations identified here expand the spectrum of SOX9 pathogenic variations to about seventy (Table S3) (Thong et al., 2000; Giordano et al., 2001; Preiss et al., 2001; Sock et al., 2003; Michel-Calemard et al., 2004; Hsiao et al., 2006; Shotelersuk et al., 2006; Beaulieu et al., 2009; Gentilin et al., 2010; Okamoto et al., 2010; Staffler et al., 2010; Kim et al., 2011; Stoeva et al., 2011; Chen et al., 2012; Gopakumar et al., 2013; Matsushita et al., 2013; Tonni et al., 2013). Premature termination codons (PTCs) are the most prevalent mutational class in $\mathrm{CD}$, accounting for approximately $45 \%$ of all the alterations identified. Consistently, six of the nine patients $(67 \%)$ in our series had a PTC mutation. In these cases, non-sense mediated mRNA decay (NMD) could potentially be employed to prevent translation of truncated peptides (Chang et al., 2007). Even if expression from the mutated alleles escaped NMD, these would generate SOX9 proteins lacking all, or at least some, of the essential domains for proper protein activity (Figure S1). 


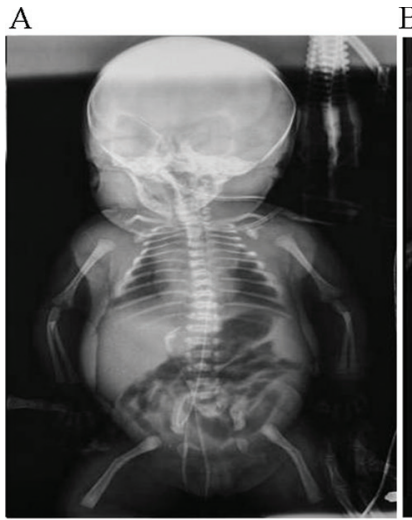

B
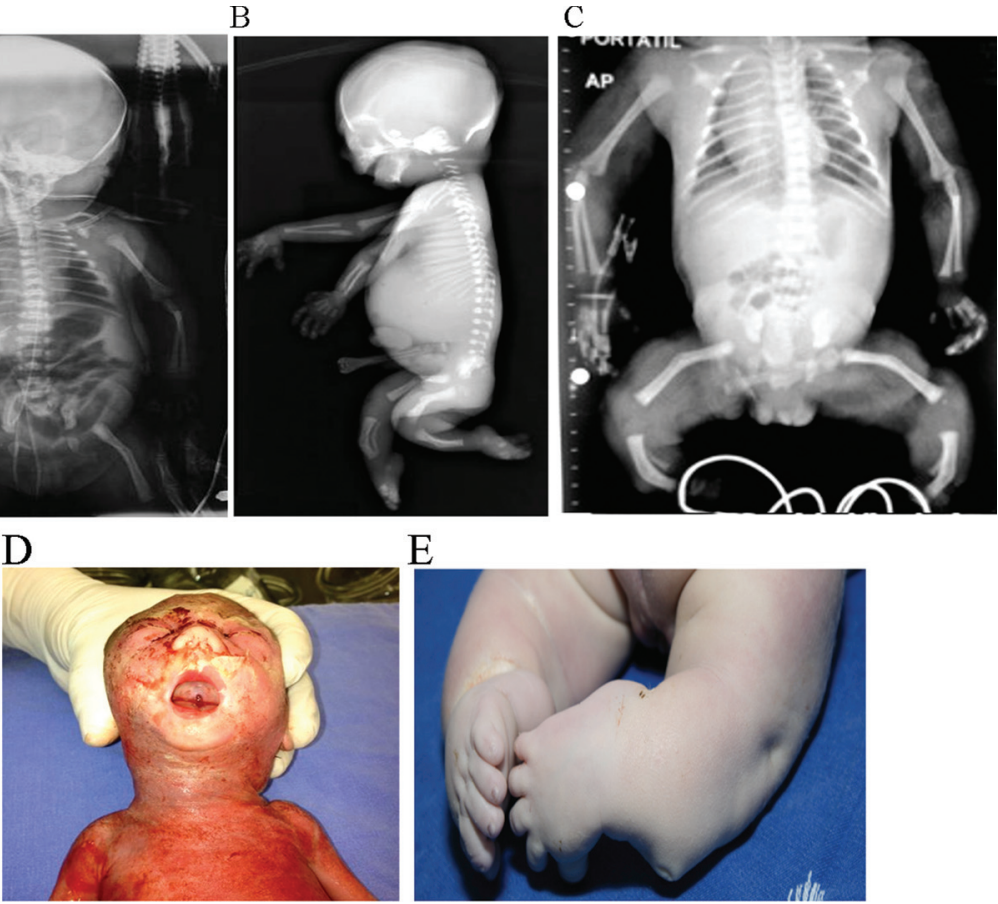

$\mathrm{E}$

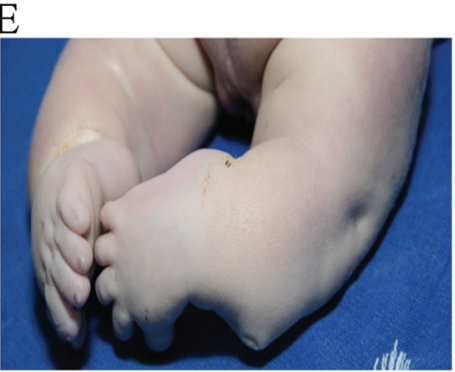

Figure 1 - Typical campomelic dysplasia findings observed in the patients included in this study. A: Antero-posterior (AP) radiography of patient 7 , showing short long bones with bowed femora and tibiae, a short thorax with eleven pairs of ribs, and hypoplastic pubic bones, although no SOX9 mutation was identified. B: Lateral radiography of patient 2. Bowing of the femora and tibiae, as well as thoracic constriction, are identifiable. C: AP radiography of patient 9. In addition to the skeletal abnormalities already described in patients 1 and 2, hypoplastic scapulae are present. D: Clinical picture of patient 2 at necropsy. A small, flat face can be observed, as well as micro- and retrognathia, and cleft palate. E: Clinical picture of patient 1 at necropsy, illustrating the club feet and the pre- and post-tibial skin dimples characteristic of CD.

A

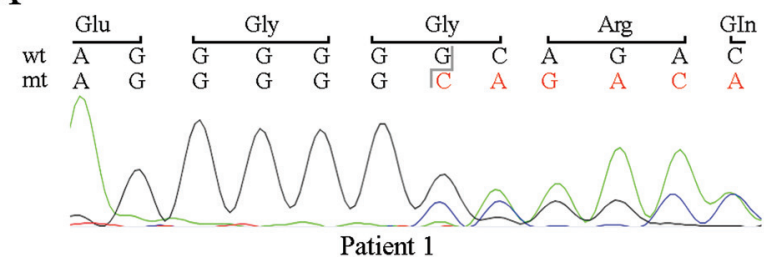

$\mathrm{C}$

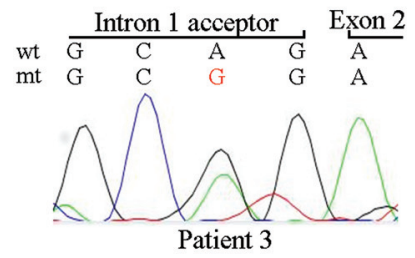

F

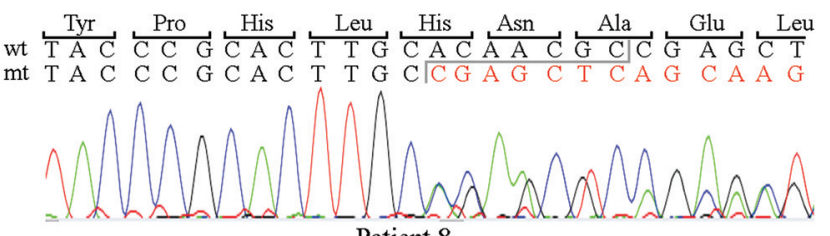

B

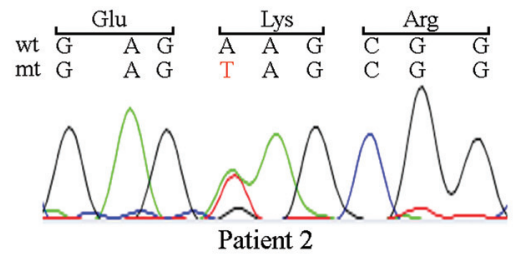

$\mathrm{E}$

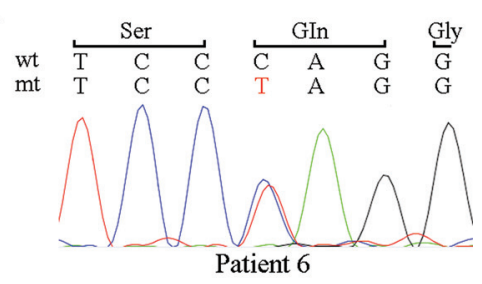

G

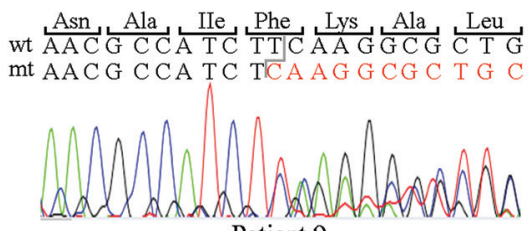

Patient 9

Figure 2 - SOX9 mutations identified in six CD patients included in the study. For each image, a fragment of the wild type (wt) allele with the corresponding codified amino acids is shown (except for $\mathrm{C}$, where the junction between the first exon and intron is depicted). Altered nucleotides in the mutant (mt) allele are depicted in red. A: frame shift mutation of patient 1 due to a 1-bp deletion. B-E: Single-nucleotide change observed in patients 2, 3, 5, and 6, respectively. F: frame shift mutation in patient 8 due to a 1-bp deletion. G: frame shift mutation in patient 9 due to a 7-bp deletion. 
Since truncated SOX9 polypeptides have been shown to retain some residual activity (Cameron et al., 1996), different authors have associated larger protein truncations with greater life expectancy of CD patients (Meyer et al., 1997; Pop et al., 2005). In this cohort, patient 1 would, theoretically, retain the largest portion of SOX9, with approximately $54 \%$ of the wild-type peptide. However, this observation did not translate into less severity, because we did not identify any correlation between the identified mutations and survival of patients.

Splice-site mutations in SOX9 account for approximately only $4 \%$ of CD mutations reported to date (see Table S3). Only one patient in this series had a splice-site mutation. This gives rise to an A-to-G transition at nucleotide position -2 from the acceptor splice-site of intron 1 (IVS1-2A > G), which was predicted in silico to affect splicing with a probability of $67 \%$. Kwok et al. (1995) identified an A-to-C transition at the same nucleotide position -2 in a female infant with typical CD findings and 46,XY karyotype (Kwok et al., 1995). Our patient had a normal 46,XX karyotype.

Interestingly, while many studies report mutations in the coding sequence of SOX9 in 46,XY sex-reversed CD individuals, we did not identify any nucleotide alteration in a patient with sex-reversal. CD patients were observed to encode mutations of any of the mutational classes already described (see Table S3). Some researchers argue that sex reversal may be a phenotype with incomplete penetrance (Meyer et al., 1997), but this proposition needs further support. Further investigations of the molecular basis of CD and related disorders are likely to contribute to a better understanding of the physiological roles of SOX9, which is a key transcription factor in the early embryonic development of several tissues.

\section{Acknowledgments}

The authors would like to thank the patients and their families for participating in this study. The technical assistance of Dr. Sandra Leistner Segal (Medical Genetics Service, HCPA) for $Z F X / S R Y$ genotyping is greatly appreciated. Financial support was partially provided by the Grupo de Pesquisa e Pós-Graduação do Hospital de Clínicas de Porto Alegre (grant 12-0467 to EPM, MTVS and LS-F) and the Conselho Nacional de Desenvolvimento Científico e Tecnológico (grants 402008/2010-3 and 590148/2011-7 to DPC).

\section{References}

Bagheri-Fam S, Barrionuevo F, Dohrmann U, Günther T, Schüle R, Kemler R, Mallo M, Kanzler B and Scherer G (2006) Long-range upstream and downstream enhancers control distinct subsets of the complex spatiotemporal Sox9 expression pattern. Dev Biol 291:382-397.

Beaulieu BM, Lemyre E, Rypens F, Scherer G, Lemieux N and Fournet J-C (2009) Diagnosis of true hermaphroditism in a fetus with acampomelic campomelic dysplasia. Prenat Diagn 29:528-530.

Cameron FJ, Hageman RM, Cooke-Yarborough C, Kwok C, Goodwin LL, Sillence DO and Sinclair AH (1996) A novel germ line mutation in SOX9 causes familial campomelic dysplasia and sex reversal. Hum Mol Genet 5:1625-1630.

Chang Y-F, Imam JS and Wilkinson MF (2007) The nonsense-mediated decay RNA surveillance pathway. Annu Rev Biochem 76:51-74.

Chen S-Y, Lin S-J, Tsai L-P and Chou Y-Y (2012) Sex-reversed acampomelic campomelic dysplasia with a homozygous deletion mutation in SOX9 gene. Urology 79:908-911.

Foster JW, Dominguez-Steglich MA, Guioli S, Kwok C, Weller PA, Stevanovic M, Weissenbach J, Mansour S, Young ID and Goodfellow PN (1994) Campomelic dysplasia and autosomal sex reversal caused by mutations in an SRY-related gene. Nature 372:525-530.

Friedrich U, Schaefer E, Meinecke P and Scherer G (2000) SOX9 mutation in a previously published case of campomelic dysplasia without overt campomelia. Clin Dysmorphol 9:233.

Fukami M, Tsuchiya T, Takada S, Kanbara A, Asahara H, Igarashi A, Kamiyama Y, Nishimura G and Ogata T (2012) Complex genomic rearrangement in the SOX9 5' region in a patient with Pierre Robin sequence and hypoplastic left scapula. Am J Med Genet A 158A:1529-1534.

Gentilin B, Forzano F, Bedeschi MF, Rizzuti T, Faravelli F, Izzi C, Lituania M, Rodriguez-Perez C, Bondioni MP, Savoldi G et al. (2010) Phenotype of five cases of prenatally diagnosed campomelic dysplasia harboring novel mutations of the SOX9 gene. Ultrasound Obstet Gynecol 36:315-323.

Giordano J, Prior HM, Bamforth JS and Walter MA (2001) Genetic study of SOX9 in a case of campomelic dysplasia. Am J Med Genet 98:176-181.

Gopakumar H, Superti-Furga A, Unger S, Scherer G, Rajiv PK and Nampoothiri S (2013) Acampomelic Form of Campomelic Dysplasia with SOX9 Missense Mutation. Indian J Pediatr 81:98-100.

Gordon CT, Tan TY, Benko S, Fitzpatrick D, Lyonnet S and Farlie PG (2009) Long-range regulation at the SOX9 locus in development and disease. J Med Genet 46:649-656.

Hsiao H-P, Tsai L-P, Chao M-C, Tseng H-I and Chang YC (2006) Novel SOX9 gene mutation in campomelic dysplasia with autosomal sex reversal. $\mathrm{J}$ Formos Med Assoc 105:1013-1016.

Kim H-Y, Yoon CH, Kim G-H, Yoo H-W, Lee BS, Kim KS and Kim EA-R (2011) A case of campomelic dysplasia without sex reversal. J Korean Med Sci 26:143-145.

Kurth I, Klopocki E, Stricker S, van Oosterwijk J, Vanek S, Altmann J, Santos HG, van Harssel JJT, de Ravel T, Wilkie AOM et al. (2009) Duplications of noncoding elements 5' of SOX9 are associated with brachydactyly-anonychia. Nat Genet 41:862-863.

Kwok C, Weller PA, Guioli S, Foster JW, Mansour S, Zuffardi O, Punnett HH, Dominguez-Steglich MA, Brook JD and Young ID (1995) Mutations in SOX9, the gene responsible for campomelic dysplasia and autosomal sex reversal. Am J Hum Genet 57:1028-1036.

Lecointre C, Pichon O, Hamel A, Heloury Y, Michel-Calemard L, Morel Y, David A and Le Caignec C (2009) Familial acampomelic form of campomelic dysplasia caused by a 
$960 \mathrm{~kb}$ deletion upstream of SOX9. Am J Med Genet A 149A:1183-1189.

Lim KH and Fairbrother WG (2012) Spliceman - A computational web server that predicts sequence variations in pre-mRNA splicing. Bioinformatics 28:1031-1032.

Maroteaux P, Spranger J, Opitz JM, Kucera J, Lowry RB, Schimke RN, Kagan SM (1971) The campomelic syndrome. Presse Med 79:1157-1162.

Massardier J, Roth P, Michel-Calemard L, Rudigoz RC, Bouvier R, Dijoud F, Arnould P, Combourieu D and Gaucherand P (2008) Campomelic dysplasia: Echographic suspicion in the first trimester of pregnancy and final diagnosis of two cases. Fetal Diagn Ther 24:452-457.

Matsushita M, Kitoh H, Kaneko H, Mishima K, Kadono I, Ishiguro N and Nishimura G (2013) A novel SOX9 H169Q mutation in a family with overlapping phenotype of mild campomelic dysplasia and small patella syndrome. Am J Med Genet A 161:2528-2534.

McDowall S, Argentaro A, Ranganathan S, Weller P, Mertin S, Mansour S, Tolmie J and Harley V (1999) Functional and structural studies of wild type SOX9 and mutations causing campomelic dysplasia. J Biol Chem 274:24023-24030.

Meyer J, Südbeck P, Held M, Wagner T, Schmitz ML, Bricarelli FD, Eggermont E, Friedrich U, Haas OA, Kobelt A et al. (1997) Mutational analysis of the SOX9 gene in campomelic dysplasia and autosomal sex reversal: Lack of genotype/phenotype correlations. Hum Mol Genet 6:91-98.

Michel-Calemard L, Lesca G, Morel Y, Boggio D, Plauchu H and Attia-Sobol J (2004) Campomelic acampomelic dysplasia presenting with increased nuchal translucency in the first trimester. Prenat Diagn 24:519-523.

Moog U, Jansen NJ, Scherer G, Schrander-Stumpel CT (2001) Acampomelic campomelic syndrome. Am J Med Genet 104:239-245

Ninomiya S, Yokoyama $\mathrm{Y}$, Teraoka $\mathrm{M}$, Mori R, Inoue $\mathrm{C}$, Yamashita S, Tamai H, Funato M and Seino Y (2000) A novel mutation (296 del G) of the SOX90 gene in a patient with campomelic syndrome and sex reversal. Clin Genet 58:224-227.

Okamoto T, Nakamura E, Nagaya K, Hayashi T, Mukai T and Fujieda K (2010) Patient reports: Two novel frameshift mutations in the SOX9 gene in two patients with campomelic dysplasia who showed long-term survival. J Pediatr Endocrinol Metab 23:1189-1193.

Pop R, Conz C, Lindenberg KS, Blesson S, Schmalenberger B, Briault S, Pfeifer D and Scherer G (2004) Screening of the 1 Mb SOX9 5' control region by array CGH identifies a large deletion in a case of campomelic dysplasia with XY sex reversal. J Med Genet 41:e47.

Pop R, Zaragoza MV, Gaudette M, Dohrmann U and Scherer G (2005) A homozygous nonsense mutation in SOX9 in the dominant disorder campomelic dysplasia: A case of mitotic gene conversion. Hum Genet 117:43-53.

Preiss S, Argentaro A, Clayton A, John A, Jans DA, Ogata T, Nagai T, Barroso I, Schafer AJ and Harley VR (2001) Compound effects of point mutations causing campomelic dysplasia/autosomal sex reversal upon SOX9 structure, nuclear transport, DNA binding, and transcriptional activation. J Biol Chem 276:27864-27872.

Sanchez-Castro M, Gordon CT, Petit F, Nord AS, Callier P, Andrieux J, Guérin P, Pichon O, David A, Abadie V et al.
(2013) Congenital heart defects in patients with deletions upstream of SOX9. Hum Mutat 34:1628-1631.

Shotelersuk V, Jaruratanasirikul S, Sinthuwiwat $\mathrm{T}$ and Janjindamai W (2006) A novel nonsense mutation, E150X, in the SOX9 gene underlying campomelic dysplasia. Genet Mol Biol 29:617-620

Sock E, Pagon RA, Keymolen K, Lissens W, Wegner M and Scherer G (2003) Loss of DNA-dependent dimerization of the transcription factor SOX9 as a cause for campomelic dysplasia. Hum Mol Genet 12:1439-1447.

Spranger JW, Brill PW, Poznanski A (2002) Bone Dysplasias An Atlas of Genetic Disorders of Skeletal Development. 2nd edition. Oxford University Press, New York, 613 pp.

Staffler A, Hammel M, Wahlbuhl M, Bidlingmaier C, Flemmer AW, Pagel P, Nicolai T, Wegner M and Holzinger A (2010) Heterozygous SOX9 mutations allowing for residual DNA-binding and transcriptional activation lead to the acampomelic variant of campomelic dysplasia. Hum Mutat 31:E1436-1444.

Stoeva R, Grozdanova L, Scherer G, Krasteva M, Bausch E, Krastev T, Linev A and Stefanova M (2011) A novel SOX9 nonsense mutation, $\mathrm{q} 401 \mathrm{x}$, in a case of campomelic dysplasia with XY sex reversal. Genet Couns 22:49-53.

Thong MK, Scherer G, Kozlowski K, Haan E and Morris L (2000) Acampomelic campomelic dysplasia with SOX9 mutation. Am J Med Genet 93:421-425.

Tommerup N, Schempp W, Meinecke P, Pedersen S, Bolund L, Brandt C, Goodpasture C, Guldberg P, Held KR and Reinwein H (1993) Assignment of an autosomal sex reversal locus (SRA1) and campomelic dysplasia (CMPD1) to 17q24.3-q25.1. Nat Genet 4:170-174.

Tonni G, Ventura A, Pattacini P, Bonasoni MP and Baffico AM (2013) p.His165Pro: A novel SOX9 missense mutation of campomelic dysplasia. J Obstet Gynaecol Res 39:1085-1091.

Wada Y, Nishimura G, Nagai T, Sawai H, Yoshikata M, Miyagawa S, Hanita T, Sato S, Hasegawa T, Ishikawa S et al. (2009) Mutation analysis of SOX9 and single copy number variant analysis of the upstream region in eight patients with campomelic dysplasia and acampomelic campomelic dysplasia. Am J Med Genet A 149A:2882-2885.

Wagner T, Wirth J, Meyer J, Zabel B, Held M, Zimmer J, Pasantes J, Bricarelli FD, Keutel J, Hustert E et al. (1994) Autosomal sex reversal and campomelic dysplasia are caused by mutations in and around the SRY-related gene SOX9. Cell 79:1111-1120.

Warman ML, Cormier-Daire V, Hall C, Krakow D, Lachman R, LeMerrer M, Mortier G, Mundlos S, Nishimura G, Rimoin DL et al. (2011) Nosology and classification of genetic skeletal disorders: 2010 revision. Am J Med Genet A 155A:943-968.

\section{Internet Resources}

Spliceman

Web

Server,

http://fairbrother.biomed.brown.edu/spliceman/index.cgi

(April 28, 2014). 


\section{Supplementary Material} ticle:

The following online material is available for this ar-

Table S1 - Detailed clinical evaluation of CD patients included in the study.

Table S2 - Detailed radiological evaluation of CD patients included in the study.

Table S3 - Compilation of all reported SOX9 mutations associated to $\mathrm{CD}$ and $\mathrm{ACD}$.
Figure S1 - Putative SOX9 proteins resultant from the premature stop codon mutations identified in six CD patients.

This material is available as part of the online article from http://www.scielo.br/gmb.

Associate Editor: Maria Luiza Petzl-Erler

License information: This is an open-access article distributed under the terms of the Creative Commons Attribution License, which permits unrestricted use, distribution, and reproduction in any medium, provided the original work is properly cited. 